\title{
Carbapenem -resistant Enterobacteriaceae: Prevalence and bacteriological profile in a tertiary teaching hospital from rural western India
}

\author{
Satyajeet K Pawar, ${ }^{1, *}$, S. T. Mohite ${ }^{2}$, R.V. Shinde ${ }^{3}$, S.R. Patil ${ }^{4}$, G.S. Karande ${ }^{5}$ \\ ${ }^{1,3}$ Associate Professor, ${ }^{2,4}$ Professor, ${ }^{5}$ Professor and Head, Dept. of Microbiology, Krishna Institute of Medical Sciences, Karad, \\ Maharashtra, India
}

*Corresponding Author:

Email: drskpawar@gmail.com

\begin{abstract}
Introduction: In last few years, Gram-negative bacilli are isolated capable of producing various classes of carbapenemases with ability of hydrolyzing the $\beta$-lactam antimicrobial. Carbapenem Resistant Enterobacteriaceae (CRE) have been reported worldwide. There is a serious threat to public health due to the emergence and rapid spread of CRE.

Aims: To find prevalence and bacterial profile of CRE in clinical isolates in indoor patients from a rural tertiary care centre.

Materials and Methods: The study was conducted in a tertiary care teaching hospital in Western India, June 2016 to April 2018. The clinical specimens received in microbiology laboratory were processed by the standard method. Bacteria were identified by VITEK 2 compact (Biomerieux) automation system, and antimicrobial susceptibility testing was done with the same system to detect minimum inhibitory concentrations for carbapenem group of antimicrobials. CLSI 2016 guidelines were used to detect CRE.

Results: Total 535 Enterobactericaeae clinical isolates were included in the study. Of these, 31.77\% (n=170) were CRE. Specimens like urine, pus/ wound swab and endotracheal tube secretion were the major contributors for CRE isolates. $82 \%$ of CRE were Klebsiella pneumoniae (63\%) and E.coli (19\%).

Conclusions: A high prevalence of $31.77 \%$ carbapenem resistance was observed among Enterobacteriaceae isolates. Early detection, isolation and contact precaution of CRE patients will help to prevent rapid dissemination of CRE infection.
\end{abstract}

Keywords: Carbapenem Resistant Enterobacteriaceae, CRE, Carbapenemase, Klebsiella pneumoniae.

\section{Introduction}

Antibiotic resistance has emerged as a major health- related issue in last few years. There have been growing epidemics of infections due to gram negative bacteria especially from Enterobacteriaceae family, which are resistant to many classes of antibiotics. ${ }^{1}$

$\beta$-lactam antimicrobial agents are the major group of antimicrobials used for the treatment of gramnegative bacterial infections. Besides extended spectrum penicillins and cephalosporins, the carbapenems have become important options for medication especially in intensive care unit patients. ${ }^{2}$ Carbapenems are agents with an exceptionally broad spectrum of activity. ${ }^{3}$ Due to extended spectrum betalactamase(ESBL) and AmpC enzyme producing Enterobacteriaceae, carbapenems are used as a last resort against many multi drug resistant, gram negative bacteria. ${ }^{4}$

But in last few years, gram negative bacilli are producing various classes of carbapenemases capable of hydrolyzing the $\beta$-lactam antimicrobial. ${ }^{5}$ Besides Pseudomonas spp. and Acinetobacter spp., Carbapenem Resistant Enterobacteriaceae (CRE) have been reported worldwide. ${ }^{6}$ Carbapenem Resistant Enterobacteriaceae can be defined as Enterobacteriaceae that are resistant to one or all of the following carbapenems: ertapenem, meropenem, imipenem or doripenem. ${ }^{7}$ Besides production of carbapenemase enzyme the other mechanism of resistance include over-expression of efflux pumps by the bacteria, lack of porins present in the bacterial cell membrane and poor binding of carbapenems to penicillin-binding proteins. ${ }^{4}$ Carbapenemase encoding gene responsible for this resistance mechanism is spread rapidly within different gram negative bacterial species. ${ }^{8}$ This inter and intra species spread occurs through horizontal plasmid mediated transmission which is common among CRE. ${ }^{8}$

There is a serious threat to public health due to the emergence and rapid spread of Carbapenem-resistant bacteria especially CRE. These CRE infections are associated with high mortality and rapid dissemination. ${ }^{8}$ Because of rapid rise in the prevalence of CRE, it is essential for early detection. Also epidemiology and bacteriology of CRE will help any health care institute for rational therapy and isolation and contact precautions of such infectious patient preventing further spread. There have been studies on detection of carbapenemase producing bacteria, from many part of the country, but not from this region of western rural India prompting to undertake the study.

\section{Materials and Methods}

The institutional ethical clearance was taken before the study project.

Study Design: Laboratory based prospective, observational study. 
Study Centre: Department of Microbiology, KIMS and KH\&MRC, Karad.

Inclusion Criteria: Non-repetitive Enterobacteriaceae strains which are Carbapenem-resistant isolated from clinical specimens.

Exclusion Criteria: Enterobacteriaceae strains which are Carbapenem sensitive.

Methodology: Total 2518 clinical specimens, received in the laboratory over a period of three years, for culture and sensitivity were included for study purpose. Specimens were pus, endotracheal secretions, sputum, urine, cerebrospinal fluid, blood, and body fluids like ascitic fluid, peritoneal fluid, pleural fluid and other specimens like catheter tips. Processing of the specimens was done as per standard methods on blood agar, Chocolate agar, and MacConkey's agar. ${ }^{9}$ Bacterial colonies were identified by VITEK 2 compact (Biomerieux) automation system and antimicrobial susceptibility testing was done with the same system to detect MIC. ${ }^{10}$ For this gram negative antimicrobial panel was used which included Imipenem, Meropenem and Ertapenem besides other antimicrobials.

Interpretation of test was done as per CLSI (2016) guidelines. MIC value of $\geq 4 \mu \mathrm{g} / \mathrm{ml}$ for Imipenem, Meropenem and $\geq 2 \mu \mathrm{g} / \mathrm{ml}$ for Ertapenem was considered as resistant to carbapenem antimicrobials. ${ }^{7}$ Quality control for bacterial identification was done by standard ATCC strain Escherichia coli 25922, Pseudomonas aeruginosa 27853, and Staphylococcus aureus $29213 .{ }^{7}$ For CRE Klebsiella pneumoniae ATCC strain BAA $-1705 \& 1706$ were used as positive and negative controls respectively. ${ }^{7}$

\section{Statistical Analysis}

Data entry was done in Excel format and was analyzed using SPSS in the form of Tables, Figures and Charts.

\section{Results}

Total 2518 specimens were processed over a period of three years. Of these clinical specimens total 1024 showed growth of either gram positive or gram negative organism. From these 535 Enterobactericae clinical isolates were included for the study. According to CLSI guidelines, $170(31.77 \%)$ of these isolates were CRE. In sex distribution male prevalence $(n=111)$ outnumbered female prevalence $(n=59) .41-60$ age group showed maximum CRE prevalence. (Fig.1)

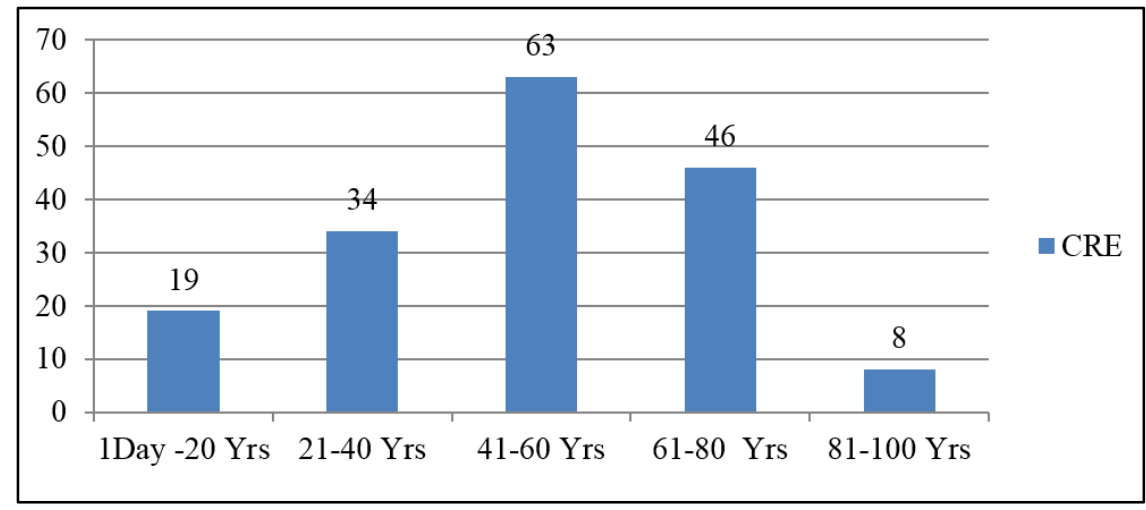

Fig. 1: Age distribution of CRE isolates

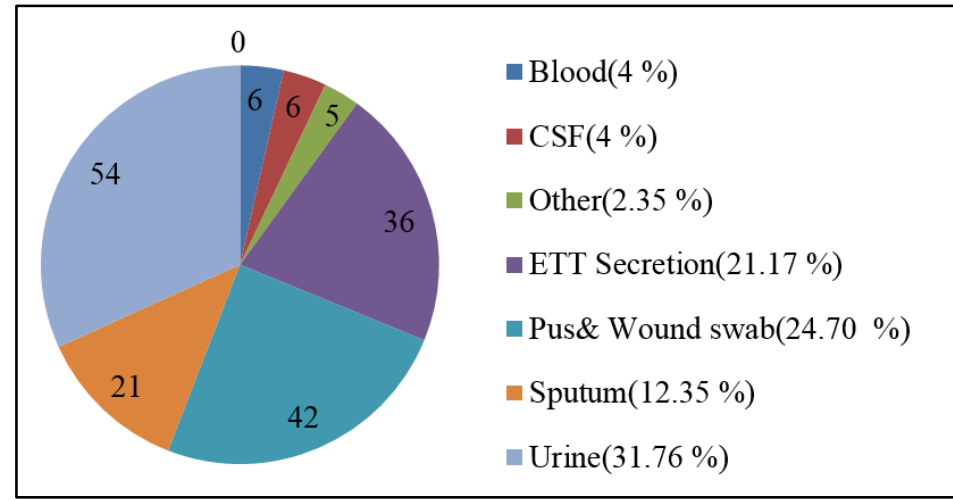

Fig. 2: Distribution of CRE in clinical specimens

Other: CVP tip, ICDT tip, Tracheostomy secretion, peritoneal fluid
Maximum isolates were from urine $(\mathrm{n}=54)$, followed by pus and wound swab $(n=42)$. ETT secretion was the third most number of isolates. (Fig. 2) 
$60 \%$ of CRE $(n=102)$ were from ICU while $40 \%(n=68)$ of isolates were from wards (Table 1).

Table 1 : Distribution of CRE in hospital

\begin{tabular}{|l|c|c|}
\hline & CRE $(\mathbf{n})$ & Percentage $(\boldsymbol{\%})$ \\
\hline ICU & 102 & 60 \\
\hline Ward & 68 & 40 \\
\hline Total & 170 & 100 \\
\hline
\end{tabular}

As shown in Fig. 3 Medicine ICU was among highest CRE contributor while among wards most CRE $(n=35)$ were isolated from Surgery.

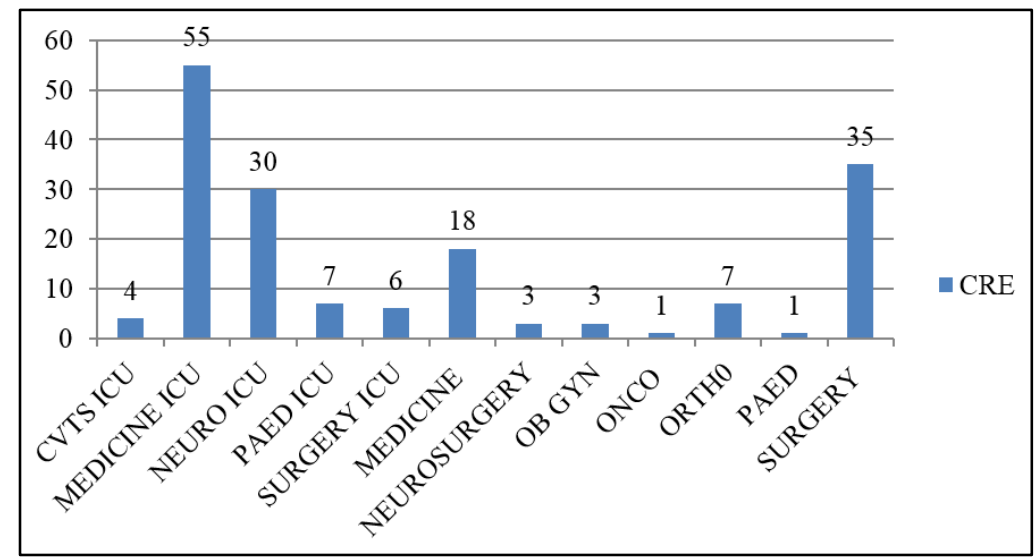

Fig. 3: ICU and ward wise distribution of CRE isolates

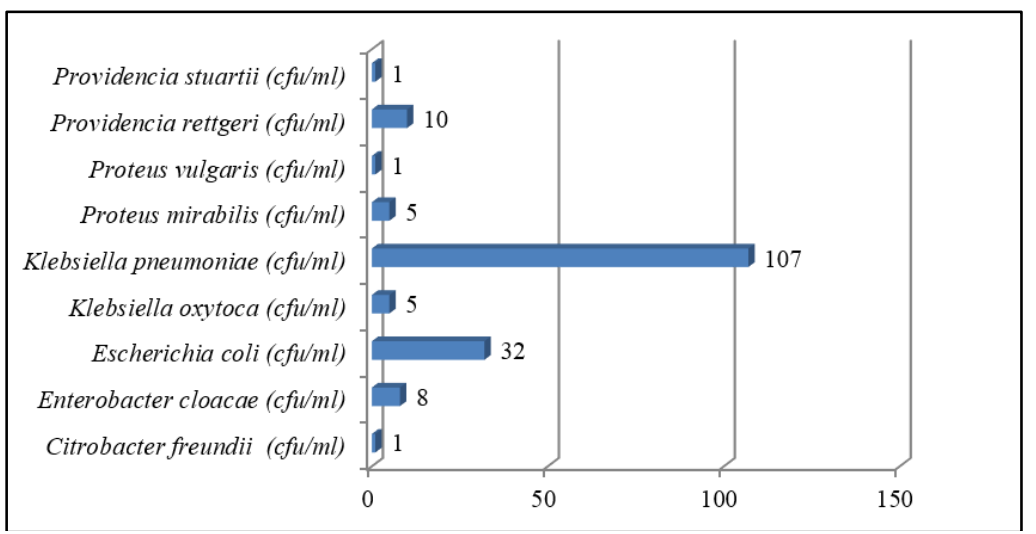

Fig. 4 Distribution of bacterial species among CRE

$63 \%(n=107)$ of all the CRE isolates were Klebsiella pneumoniae while $19 \% \quad(\mathrm{n}=32)$ were Escherichia coli. (Fig. 4) The other isolates in

Enterobacter cloacae, Klebsiella oxytoca, Proteus mirabilis, Proteus vulgaris, Citrobacter freundii, Providencia stuartii. decreasing order were Providencia rettgeri,

Table 2: Distribution of CRE isolates among different clinical specimens

\begin{tabular}{|c|c|c|c|c|c|c|c|c|c|c|}
\hline Bacterial species & $\begin{array}{l}\text { Peritoneal } \\
\text { fluid }\end{array}$ & $\begin{array}{l}\text { CVP } \\
\text { Tip }\end{array}$ & Sputum & Urine & $\begin{array}{c}\text { Pus\& } \\
\text { Wound } \\
\text { swab } \\
\end{array}$ & Blood & $\begin{array}{c}\text { ETT } \\
\text { Secretion }\end{array}$ & $\begin{array}{c}\text { Tracheaostomy } \\
\text { Secretion }\end{array}$ & CSF & $\begin{array}{c}\text { ICDT } \\
\text { Tip }\end{array}$ \\
\hline $\begin{array}{l}\text { Citrobacter freundii } \\
(\mathrm{cfu} / \mathrm{ml})\end{array}$ & 0 & 0 & 0 & 0 & 1 & 0 & 0 & 0 & 0 & 0 \\
\hline $\begin{array}{l}\text { Enterobacter } \\
\text { cloacae }(\mathrm{cfu} / \mathrm{ml})\end{array}$ & 0 & 0 & 0 & 2 & 2 & 0 & 2 & 0 & 2 & 0 \\
\hline $\begin{array}{l}\text { Escherichia coli } \\
(\mathrm{cfu} / \mathrm{ml})\end{array}$ & 0 & 0 & 3 & 17 & 10 & 0 & 2 & 0 & 0 & 0 \\
\hline $\begin{array}{l}\text { Klebsiella oxytoca } \\
(\mathrm{cfu} / \mathrm{ml})\end{array}$ & 0 & 0 & 1 & 1 & 3 & 0 & 0 & 0 & 0 & 0 \\
\hline $\begin{array}{l}\text { Klebsiella } \\
\text { pneumoniae (cfu/ml) }\end{array}$ & 1 & 1 & 17 & 23 & 22 & 6 & 30 & 2 & 4 & 1 \\
\hline
\end{tabular}




\begin{tabular}{|c|c|c|c|c|c|c|c|c|c|c|}
\hline $\begin{array}{l}\text { Proteus mirabilis } \\
(\mathrm{cfu} / \mathrm{ml})\end{array}$ & 0 & 0 & 0 & 1 & 3 & 0 & 1 & 0 & 0 & 0 \\
\hline Proteus vulgaris & 0 & 0 & 0 & 0 & 1 & 0 & 0 & 0 & 0 & 0 \\
\hline $\begin{array}{l}\text { Providencia rettgeri } \\
(\mathrm{cfu} / \mathrm{ml})\end{array}$ & 0 & 0 & 0 & 10 & 0 & 0 & 0 & 0 & 0 & 0 \\
\hline $\begin{array}{l}\text { Providencia stuartii } \\
(\mathrm{cfu} / \mathrm{ml})\end{array}$ & 0 & 0 & 0 & 0 & 0 & 0 & 1 & 0 & 0 & 0 \\
\hline Total $(n=170)$ & 1 & 1 & 21 & 54 & 42 & 6 & 36 & 2 & 6 & 1 \\
\hline
\end{tabular}

Most Klebsiella pneumoniae were isolated from ETT secretion $(\mathrm{n}=30)$ followed by urine $(\mathrm{n}=23)$ and pus and wound swab $(\mathrm{n}=22)$. (Table 2). Maximum E.coli $(n=17)$ were isolated from urine. While all the CRE from blood were Klebsiella pneumoniae, all
Providencia rettgeri isolated were from urine specimens. (Table 2). These total $170 \mathrm{CRE}$ were isolated over a period of three years. One of the important findings, was prevalence reduced from $37.20 \%$ in 2016 to $21.33 \%$ in 2018. (Table 3).

Table 3: Year wise distribution of CRE

\begin{tabular}{|l|c|c|c|}
\hline \multicolumn{1}{|c|}{ Year } & Enterobacteriaceae(n) & CRE(n) & CRE (\%) \\
\hline 2016 & 129 & 48 & 37.20 \\
\hline 2017 & 293 & 98 & 33.44 \\
\hline 2018 & 113 & 24 & 21.23 \\
\hline Total & 535 & 170 & 31.77 \\
\hline
\end{tabular}

\section{Discussion}

Prevalence of CRE in the present study was $31.77 \%$. Kumarasami et al found $23.7 \%$ prevalence rate of CRE from isolates from Hariyana. ${ }^{11} 13$ to $51 \%$ prevalence rate was noted by Wattal et al in a tertiary care hospital from Delhi. ${ }^{12}$ In a study in Mumbai, Nair et al found it around $12.26 \% .{ }^{13} \mathrm{~A}$ range of 17 to $22 \%$ was observed by Gupta et al in a study in northern India. ${ }^{14}$ The present study was carried out in 1125 bedded multispecialty tertiary care hospital from rural western India. Most patients are referred after already receiving antimicrobials. Also $60 \%$ of the isolates in the study were from ICU where patients are likely to undergo invasive procedure. ${ }^{15}$ These factors and longer duration of hospital stay might have contributed for the high prevalence of CRE in the study. ${ }^{15}$

In India like developed countries noncommunicable disease, accidents and injury are becoming the leading cause for hospitalsation. ${ }^{16}$ This explains the reason for more number of patients having age more than 40 years in the study. Also, they are likely to get intervention as a part of indoor patient management, contributing to CRE infection. These include healthcare and long term care exposure, invasive devices, drains and endotracheal entubation. ${ }^{17}$ Urine $(31.76 \%)$ was the leading specimen for CRE isolates. In the study of Nair et $\mathrm{al}^{13}(42 \%)$ and Singh et $\mathrm{al}^{18}(39.4 \%)$ again urine was leading specimen contributing carbapenemase producing isolates. Medicine ICU $(\mathrm{n}=55)$ while among wards surgery ward $(n=35)$ showed maximum CRE isolates. In study by Nagaraj et al most carbapenemase producing isolates were from general surgery, general medicine, and ICU. ${ }^{19}$

The majority of organisms in human gut flora are from Enterobactericeae family. Furthur carbapenemase producing Enerobacteriaceae are spread rapidly because of horizontal transmission of plasmid encoding genes responsible for carbapenemase production. This occurs mainly by faeco-oral route in communityacquired infections as well as in hospitalized patients. ${ }^{20}$ Because of this close proximity urine specimens show more CRE prevalence. Also poor health care person and patients hand hygiene compliance may contribute for high prevalence in surgery patients. ${ }^{17,20}$ Longer duration of stay and invasive procedure which is common in ICU patients, are major risk factors for CRE infections. ${ }^{21}$

In the present study $82 \%$ of CRE were Klebsiella pneumoniae (63\%) and E.coli (19\%). Similar findings were observed in northern Indian study by Chattergy et al where $66 \%$ of total CRE were Klebsiella pneumoniae and E.coli. ${ }^{22}$ Lorenzoni et al found $95.7 \%$ of strains of Klebsiella pneumoniae responsible for carbapenemase production. $^{23}$ Major gene responsible for carbapenemase production in India associated in these organisms is bla $a_{\mathrm{NDM} 1}$. Universal presence of this gene in CRE has been proven in various Indian studies. ${ }^{11,22}$ bla $a_{\mathrm{NDM} 1}$ gene is present in many unrelated gram negative bacilli including Enterobacteriaceae family. Also more worrisome is population of more than 1.4 billion in Indian subcontinent is a major threat for rapid dissemination of CRE. ${ }^{20}$

All the blood CRE isolates in present study were Klebsiella pneumoniae. Sekhar et al has documented significant proportion of Klebsiella pneumoniae compared to E.coli in blood stream infections caused by CRE. ${ }^{24}$ Problem with carbapenemase producing bacteria is delay in its confirmation in average laboratory set up. Though molecular methods are gold standard, has its own limitation in the form of time consumtion and cost effectiveness. In a laboratory setup with automation 
facility like ours, MIC detection will aid in early detection of CRE. ${ }^{13}$ This will help in providing contact precautions for the patients. Infact, in the present study, it was found that prevalence of CRE reduced from $37.2 \%$ in 2016 to $21.33 \%$ in 2018. The hospital staff has undergone continued medical education on hand hygiene as part of training process of National Accreditation Board of Hospital and Health Care Providers. This has improved hand hygiene compliance of the health care persons. ${ }^{25}$ This may be one of the factor responsible for decreasing CRE prevalence over period of three years although it requires to be confirmed by epidemiological study.

For prevention of CRE infection various control measures have been proposed. ${ }^{26}$ These include early laboratory detection, infection control measures in the form of contact precaution, hand hygiene, isolation proper medical waste disposal, restricted use of invasive devices, epidemiological screening of rectal and perirectal swabs and antibiotic stewardship. ${ }^{26}$

\section{Conclusion}

The emergence of CRE has become major public health issue. A high prevalence of $31.77 \%$ carbapenem resistance was observed among Enterobacteriaceae isolates. $82 \%$ of these CRE, were Klebsiella pneumoniae and E.coli. Improved compliance in hand hygiene technique may be one of the findings, responsible for reduced prevalence of the CRE over a period of three year in the study. This further emphasizes role of early detection, isolation and contact precaution of CRE patients to prevent rapid dissemination of carbapenemase encoded genes present on the plasmids. There should be restricted use of Carbapenem antimicrobials to prevent further escalation of carbapenem-resistance, which underlines the importance of strict implementation of Antimicrobial Stewardship Programme.

\section{References}

1. Peleg AY, Hooper DC. Hospital-Acquired Infections Due to Gram-Negative Bacteria. $N$ Engl J Med. 2010;362(19):1804-1813.

2. Pawar SK, Patil SR, Karande GS, Mohite ST, Pawar VS. Antimicrobial Sensitivity Pattern of Clinical Isolates in Intensive Care Unit in a Tertiary Care Hospital from Western India. Int J Sci Stud. 2016;4(2):108-113.

3. Papp-Wallace KM, Endimiani A, Taracila MA, Bonomo RA. Carbapenems: Past, Present, and Future. Antimicrobs Agents Chemother.2011;55(11):4943-4960.

4. Datta P, Gupta V, Garg S, Chander J. Phenotypic method for differentiation of carbapenemases in Enterobacteriaceae: Study from north India. Indian $J$ Pathol Microbiol. 2012;55:357-360.

5. Hrabak J, Chudackova E, and Papagiannitsis CC. Detection of carbapenemase in Enterobacteriaceae: a challenge for diagnostic microbiological laboratories. Clin Microbiol Infect. 2014;20(9):839-53.

6. Deshpande P, Rodrigues C, hetty A, Kapadia F, Hedge A, Soman R. New Delhi Metallo- $\beta$ lactamase (NDM-1) in Enterobacteriaceae: Treatment options with Carbapenems
Compromised. J Assoc Physician India. 2010;58:147149.

7. Clinical and Laboratory Standards Institute. Performance Standards for Antimicrobial Susceptibility Testing; CLSI document M100-S26.Wayne PA: Clinical and Laboratory Standards Institute; 2016.

8. Diene SM, Rolain JM. Carbapenemase genes and genetic platforms in Gram-negative bacilli: Enterobacteriaceae, Pseudomonas and Acinetobacter species. Clin Microbiol Infect. 2014;20:831-838.

9. Collee JG, Miles RS, Watt B, Tests for the identification of bacteria, In: Collee JG, Fraser AG, Marmion BP, Simmons A, Mackie and McCartney Practical Medical Microbiology.14th Ed. Churchill Livingstone, 1996:135.

10. Pawar SK, Karande GS, Shinde RV, Pawar VS. Emergence of Colistin Resistant Gram Negative Bacilli, in a Tertiary Care Rural Hospital from Western India. Indian J Microbiol Res. 2016;3(3):308-313.

11. Kumarasamy KK, Toleman MA, Walsh TR, Bagaria J, Butt F, Balakrishnan R, et al. Emergence of a new antibiotic resistance mechanism in India, Pakistan, and the UK: a molecular, biological, and epidemiological study. Lancet Infect Dis. 2010;10:597-602.

12. Wattal C, Goel N, Oberoi JK, Raveendran R, Datta S, Prasad KJ. Surveillance of multidrug resistant organisms in tertiary care hospital in Delhi, India. $J$ Assoc Physicians India. 2010;58:32-36.

13. Nair PK, Vaz MS. Prevalence of carbapenem resistant Enterobacteriaceae from a tertiary care hospital in Mumbai. India J of Microbiology and Infectious Diseases. 2013;3(4):207-210.

14. Gupta E, Mohanty S, Sood S, et al. Emerging resistance to carbapenems in a tertiary care hospital in north India. Indian J Med Res. 2006;124:95-98.

15. Porwal R, Gopalakrishnan R Naga JR, Ramasubramanian V. Carbapenem resistant Gram-negative bacteremia in an Indian intensive care unit: A review of the clinical profile and treatment outcome of 50 patients. Indian J Crit Care Med. 2014;18(11):750-753.

16. Kastor A, Mohanty SK. Disease and age pattern of hospitalisation and associated costs in India: 19952014.BMJ Open. 2018;8:e16990. doi: 10.1136/bmjopen2017-016990.

17. Duina D, Doib Y. The global epidemiology of carbapenemase-producing Enterobacteriaceae. Virulence. 2017;8(4):460-469.

18. Singh S, Samant SA, Bansal M, Talukdar A, Arif D. Phenotypic Detection of Carbapenemase Producing Gram Negative Bacteria by Modified Hodge Test. Int J Curr Microbiol App Sci. 2016;5(11):315-20.

19. Nagaraj S, Chandran SP, Shamanna P, Macaden R. Carbapenem Resistance among Escherichia coli and Klebsiella pneumoniae. In a Tertiary Care Hospital in South India. Indian J Med Microbiol. 2012;30:93-95.

20. Nordmann P, Naas T, Poirel L Global Spread of Carbapenemase - producing Enterobacteriaceae. Emerging Infectious Diseases. 2011;17(10):1791-1798.

21. Lee HJ, Choi JK, Cho SY, Kim SH, Park SH, Choi SM. Carbapenem-resistant Enterobacteriaceae: Prevalence and Risk Factors in a Single Community-Based Hospital in Korea. Infect Chemother. 2016;48(3):166-173.

22. Chatterjee B, Khanduri N, Kakati B, Kotwal A. Universal

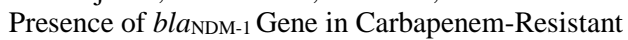
Gram-Negative Bacilli in an Indian Hospital in 2015.J Clin Diagn Res. 2017;11(9):DL01-DL02.

23. Lorenzoni VV. Silva D, Rampelotto RF, Brats PC, Villa B, Hörner R. Evaluation of carbapenem-resistant Enterobacteriaceae in a tertiary-level reference hospital in 
Rio Grande do Sul, Brazil. Rev Soc Bras Med. Trop. 2017;50(5).http://dx.doi.org/10.1590/0037-86820209-2017

24. Sekar R, Mythreyee M, Srivani S, Sivakumaran D, Lallitha S, Saranya S. Indian Pediatr. Carbapenemresistant Enterobacteriaceae in Pediatric Bloodstream Infections in Rural Southern India. Indian Pediatr. 2017;54(12):1021-1024.

25. Pawar SK, Patil RR, Shinde RV, Karande GS.

Knowledge, attitude, practice of hand hygiene among nursing staff in medicine ICU in a tertiary health care centre in Western India. Int $J$ Med Biomed Res.2018;09(05):184-187.
26. CDC guidelines for control of Carbapenem resistant or Carbapenem producing Enterobacteriaceae in Acute care facilities. 2014.

How to cite this article: Pawar SK, Mohite ST, Shinde RV, Patil SR, Karande GS. Carbapenemresistant Enterobacteriaceae: Prevalence and bacteriological profile in a tertiary teaching hospital from rural western India. Indian $\mathbf{J}$ Microbiol Res. 2018;5(3):342-347. 